Informação

v. 1, n. 2

jul./dez. 2019

E-ISSN: 2674-6549
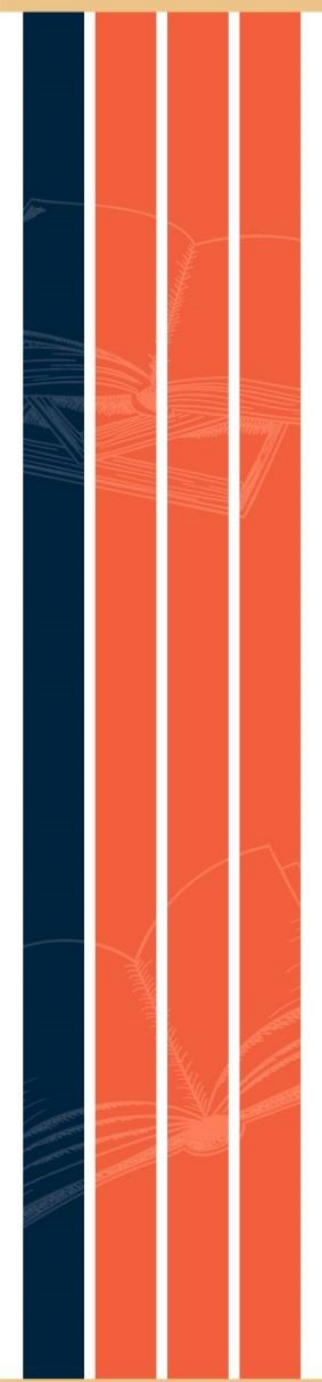

Submissão: 02/05/2019 Aprovação: 05/08/2019

\title{
PROCEDIMENTOS DOCENTES PARA INGRESSO DE PESSOAS COM DEFICIÊNCIAS (PCDs) NO ENSINO SUPERIOR
}

\author{
TEACHING PROCEDURES FOR THE ENTRY OF DISABLED \\ PEOPLE (PCDS) IN HIGHER EDUCATION
}

\author{
Alboni Marisa Dudeque Pianovski Vieira ${ }^{1}$ \\ Levino Bertochi Junior ${ }^{2}$ \\ Pryscila Alves dos Santos ${ }^{3}$
}

\begin{abstract}
RESUMO
O artigo analisa a percepção dos professores do ensino médio regular da rede pública estadual do Alto Uruguai Gaúcho perante a maneira na qual os professores integram seus alunos PCDs (pessoas com deficiências) em fase de acesso ao ensino superior, a partir de suas estratégias de docência. Este estudo caracteriza-se como uma pesquisa exploratória com características descritivas, no qual o instrumento de coleta de dados foram as entrevistas semiestruturadas. Verificou-se que as metodologias utilizadas nas salas de aula regulares favorecem o processo de ensino e aprendizagem dos PCDs, bem como constatou-se que houve melhoras na aprendizagem com a sala de recursos. Existem encontros e atividades extraclasses para os alunos, contudo percebe-se que os docentes não estão inteiramente capacitados para atender às necessidades de alunos PCDs em fase de acesso ao ensino superior.
\end{abstract}

Palavras-chave: Inclusão. Pessoas com Deficiência. Técnicas de Ensino. Docentes.

\begin{abstract}
The article analyzes the perception of high school teachers in the state public network of Alto Uruguai Gaúcho regarding to the way teachers integrate their PWDs (people with disabilities) students in the access phase to universities, based on their teaching strategies. This study is characterized as an exploratory research with descriptive characteristics, in which the instrument of data collection was formed by semistructured interviews. It was verified that the methodologies used in regular classrooms favor the process of teaching and learning of PWDs, as well as it was noted that there were improvements in learning with the resource room. There are extra class meetings and activities for the students, however, it is noticed that teachers are not fully qualified to meet the needs of PWD students in the access phase to higher education.

Keywords: Inclusion. People with Disabilities. Teaching Techniques. Teachers.
\end{abstract}

${ }^{1}$ Doutora em Educação pela Pontifícia Universidade Católica do Paraná (PUCPR). Graduação em Pedagogia pela Pontifícia Universidade Católica do Paraná (PUCPR). Professora da Pontifícia Universidade Católica do Paraná. Lattes: http://lattes.cnpq.br/0198429449537597. Orcid: https://orcid.org/0000-0003-3759-0377. E-mail: alboni@alboni.com.

${ }^{2}$ Mestrado em Administração pela Pontifícia Universidade Católica do Paraná (PUCPR). Graduação em Administração pela Pontifícia Universidade Católica do Paraná (PUCPR). Lattes:

http://lattes.cnpq.br/5523172706230423. Orcid: https://orcid.org/0000-0002-2091-2168. E-mail: levinojunior@gmail.com.

${ }^{3}$ Mestranda em Administração pela Pontifícia Universidade Católica do Paraná (PUC/PR).

Graduação em Marketing pela Pontifícia Universidade Católica do Paraná (PUC/PR). Analista de Comunicação Integrada de Marketing PL. Lattes: http://lattes.cnpq.br/5401424529719173. Orcid: https://orcid.org/0000-0002-8806-6930. E-mail: pryscila.mkt@gmail.com. 


\section{INTRODUÇÃO}

À sombra do sistema educacional brasileiro, há um cluster de indivíduos que margeiam o processo de escolarização, esse grupo é o das Pessoas Com Deficiência (PCDs). Essa marginalização e a ânsia de retificá-la se constituem como a razão pela qual há diversas leis, decretos e resoluções criados a despeito da inclusão e da educação deste grupo.

Outrora, na fundação dos direitos dos PCDs, sabe-se que muitas das iniciativas partiram de familiares de pessoas com deficiência que enfrentavam e enfrentam dificuldades em seu cotidiano (BRAGA; SCHUMACHER, 2013). Em matéria assinada por Theyse Viana (2017), o Diário do Nordeste elucida as intempéries diárias de PCDs com um caso análogo que pode ser verificado em diferentes situações. Alguns exemplos relatados pela entrevistada, Diana Barroso, foram: "É deficiente, mas é tão bonitinha...", "Tu casou? Como é que pode?", "Mas teu marido é deficiente também, né?", "Teus filhos nasceram normais?". Essas são algumas das questões que pessoas com deficiência enfrentam todos os dias, como prediz o título da reportagem "A discriminação ainda é a maior barreira para a acessibilidade".

Mesmo em ambientes que propiciam o entendimento e absorção de informação, como a universidade, o preconceito ainda está impresso nas atitudes de muitos, inclusive, docentes. Em 2018, a acadêmica Laiza Rebouças, que é surda, relatou para a pesquisadora Bárbara Maria: "Era muito ruim copiar as falas do professor e ainda acompanhar a tradução feita pela intérprete, eram poucos que tinham paciência para repetir caso os estudantes tivessem alguma dúvida. Como eles falavam muito rápido, prejudicava muito o meu entendimento e aprendizado" (MARIA, 2018).

Dado este cenário, entende-se que preparar o aluno para o ensino superior é uma das tarefas fulcrais de professores de ensino médio. No tocante às pessoas com deficiência, o desafio é ainda maior, assim, investigar de que maneira os professores do Alto Uruguai Gaúcho integram seus alunos PCDs em fase de acesso ao ensino superior, a partir de suas estratégias de docência, constitui-se objetivo desta pesquisa. 
Para tanto, acredita-se que (i) identificar as metodologias utilizadas nas salas de aula regulares que podem favorecer o processo de ensino e aprendizagem com PCDs em fase de acesso ao ensino superior; (ii) verificar se ocorre mudança na aprendizagem com o uso de recursos didáticos adaptados a partir da percepção dos docentes; (iii) verificar se existem encontros ou atividades extraclasses para os alunos PCDs em fase de acesso ao ensino superior e (iv) analisar se os docentes são capacitados para atender as necessidades de alunos PCDs em fase de acesso ao ensino superior são os objetivos específicos deste estudo.

Denomina-se de Alto Uruguai Gaúcho os 30 municípios que se localizam na mesorregião do Rio Grande do Sul. Dentre as cidades, cabe ressaltar a cidade de Erechim que possui a Universidade Federal da Fronteira Sul (UFFS), destaque em Inclusão Social e pesquisa acadêmica em toda região sul do país, e o Instituto Federal de Educação, Ciência e Tecnologia (IFRS), bem como a Universidade Regional Integrada do Alto Uruguai e das Missões (URI - Erechim) (PREFEITURA MUNICIPAL DE ERECHIM, 2018). A região de estudo foi escolhida por conveniência e facilidade de acesso aos dados.

Esta pesquisa divide-se nas seguintes seções: (i) Pessoas com Deficiência, (ii) A legislação sobre PCDs no Brasil; (iii) PCDs nas Escolas Públicas Brasileiras; (iv) PCDs e o acesso ao ensino superior brasileiro. Quanto à $(\mathrm{v})$ metodologia, menciona-se os tipos de pesquisa utilizados, bem como sua modalidade da análise e as características da região de estudo escolhida. Por fim, apresentam-se as (vi) análises dos dados e as (vii) considerações finais.

\section{PESSOAS COM DEFICIÊNCIA (PCDs)}

A legislação brasileira conceitua deficiência como "toda a perda ou anormalidade de uma estrutura ou função psicológica, fisiológica ou anatômica que gere incapacidade para o desempenho de atividade dentro do padrão considerado normal para o ser humano" (BRASIL, 1989). Ademais, o Decreto Federal 3.398/99 considera em seu artigo quarto que $\mathrm{O} P C D$ se enquadra em uma das seguintes 
situações: deficiência física, deficiência auditiva, deficiência visual, deficiência mental (ou intelectual) e deficiência múltipla (BRASIL, 1999).

De acordo com este Decreto estas são as definições das deficiências:

- Deficiência física: alteração completa ou parcial de um ou mais segmentos do corpo humano, acarretando o comprometimento da função física, exceto as deformidades estéticas e a que não produzam dificuldades para o desempenho de funções;

- Deficiência Auditiva: perda parcial ou total das possibilidades auditivas sonoras, variando de graus e níveis descritos na lei;

- Deficiência Visual: prejuízo da visão em níveis incapacitantes para o exercício de tarefas da vida diária;

- Deficiência Mental: incidência simultânea de dois fatores determinantes: (a) funcionamento intelectual significativo ente inferior ao da média, com manifestação antes dos dezoito anos; (b) limitações associadas a duas ou mais áreas de habilidades adaptativas, tais como: comunicação; cuidado pessoal; habilidades sociais; saúde e segurança; habilidades acadêmicas; lazer; trabalho;

- Deficiência Múltipla: incidência de duas ou mais deficiências em uma mesma pessoa- (BRASIL, 1999).

No cenário contemporâneo, o termo mais correto e não pejorativo a ser utilizado para se referir a uma pessoa que apresenta carência de habilidades, seja física, intelectual, auditiva ou visual, é Pessoas com Deficiência (PCDs) (LEITE, 2013). Leite (2013) defende que o emprego de termos obsoletos e não pareados com a legislação perpetua e reforça preconcepções errôneas, bem como pode ser a razão da dificuldade que o público leigo e os profissionais mudam suas lógicas e cognições perante a situação de PCDs.

Leite (2013) avança o raciocínio e afirma que, apenas em 2010 - por intermédio da Resolução no 1/2010 do Conselho Nacional dos Direitos da Pessoa Portadora de Deficiência (CONADE) -, o uso da terminologia PCD foi oficialmente adotado no Brasil. 


\section{A LEGISLAÇÃO SOBRE PCDS NO BRASIL}

Há pouco mais de cinco décadas, a Lei de Diretrizes e Bases, por intermédio dos artigos 88 e 89, reforça e acentua as ideias basilares da Declaração Universal de 1948 que prevê o direito à educação pública e gratuita para todas as pessoas com deficiência (BRASIL, 1961). A disseminação de informações permitiu nos anos de 1970 a aprovação da Declaração de Diretos das Pessoas Deficientes pela Organização das Nações Unidas.

Nesta se reafirma o papel do ente com deficiência como um cidadão com plenas capacidades, dentro de suas limitações. Esta declaração enfatiza os princípios de proteção e garantia do bem-estar e reabilitação daqueles que estão em desvantagem física ou mental (DECLARAÇÃO DE DIREITO DAS PESSOAS DEFICIENTES, 1975).

Ainda com o propósito de garantir os direitos, em outubro de 1989, sanciona-se a Lei 7.853 , cujo objetivo visa assegurar o pleno exercício dos direitos individuais e sociais dos PCDs. No tocante à área de educação, destaca-se o oferecimento obrigatório de programas de educação especial no pré-escolar e a possibilidade de bolsas de estudo as pessoas com deficiência (BRASIL, 1989).

Com o enunciado fundamental de que há falta de abordagem de princípios, políticas e práticas na área das necessidades educativas educacionais, em 1994, a Declaração de Salamanca trouxe uma nova perspectiva na qual examina pontos de vista e reconsidera os deveres dos professores, visando os conhecimentos específicos para estes profissionais em diferentes níveis de ensino (DECLARAÇÃO DE SALAMANCA, 1994).

Entre as evoluções legais, em 2008, a Política Nacional de Educação Especial norteia o Atendimento Educacional Especializado (AEE) em escolas regulares. Com isso, objetiva-se o acesso, a participação e a aprendizagem dos alunos da educação especial que estão matriculados nas escolas regulares. Seu sentido é de orientar o funcionamento das escolas para que elas ofereçam as melhores respostas a cada caso de necessidade desses alunos em suas realidades (BRASIL, 2008). 
No mesmo ano, o Governo Federal e a UNESCO assinaram o Plano Nacional de Educação em Direitos Humanos, que explícita ações programáticas que visam a "fomentar a inclusão, no currículo escolar, das temáticas relativas a gênero, raça e etnia, religião, pessoas com deficiências, bem como todas as formas de discriminação e violações de direitos" (PLANO NACIONAL DE EDUCAÇÃO EM DIREITO HUMANOS, 2007, p. 33).

Contudo, somente em 2015, um conjunto de leis e decretos sobre acessibilidade, denominado Lei Brasileira de Inclusão (LBI), imprime-se no cenário legal, com o desígnio de regular a inclusão em todos os seus aspectos (BRASIL, 2015). Tais propostas moldaram e permanecem modificando as instituições, não somente no tocante estrutural mas também na constituição de uma cultura educacional, calcada em concepções inclusivas voltadas à educação para a convivência e respeito à diversidade (SANTOS, 2017). Ante a legislação brasileira exposta, percebe-se que se assegura o acesso de estudantes PCDs no ensino básico, fundamental e superior.

O Mistério da Educação, por intermédio do Sistema Nacional de Avaliação da Educação Superior (SINAES), garante o acesso e a permanência dos estudantes nas instituições de ensino, por exemplo, com as ações do projeto Incluir (2005-2008) do MEC, que promoveu condutas focadas na permanência dos estudantes PCDs nas instituições federais de ensino (MARTINS et al., 2017), ou mesmo; com a instituição das novas diretrizes avaliativas que possuem critérios que compreendem questões de acessibilidade como parte integrante do score das instituições (GARCIA et al. 2018).

Uma análise da legislação brasileira a respeito de PCDs permite constatar que o estabelecimento dessas normas tem sua iniciativa no poder público, que viabiliza a acessibilidade e permanência de alunos com necessidades especiais na Educação Superior, sendo que os critérios para essa efetivação são cada vez mais especificados (GARCIA et al., 2018). Contudo, a realidade apresentada demonstra falhas importantes na efetivação de ações de inclusão efetiva (GARCIA et al., 2018). 


\section{PCDs NAS ESCOLAS PÚBLICAS BRASILEIRAS}

Dado a conjuntura de leis brasileiras que garantem e protegem os direitos dos PCDs, desde 2008, o número de matriculados em escolas regulares superou o das destinadas ao ensino especializado (SANTOS, 2017), o que não significa que estas estejam preparadas para receber tal número (MEC, 2017). As informações de PCDs em idade escolar não são precisas e não possuem paridade em relação a cada caracterização de deficiência (SANTOS, 2017).

De acordo com o Censo Escolar da Educação Básica 2017, o índice de inclusão de PCDs nas escolas públicas ascendeu de 85,5\% em 2013 para 90,9\% em 2017 (MEC, 2017). O índice apresenta crescimento há quatro anos consecutivos. A maior parte dos alunos com deficiência, porém, não possui atendimento educacional direcionado às intempéries porvindouras na educação, por exemplo, apenas $62,2 \%$ das escolas possuem banheiros adequados para pessoas com deficiência no ensino médio ( $O$ GLOBO, 2018).

No quesito de matrículas na idade pré-escolar, em 2017, o número de PCDs matriculados na rede regular foi de 79.749. No ensino fundamental, o grupo efetuou 768.360 matrículas. E, no que tange ao ensino médio, 94.274 PCDs foram matriculados (O GLOBO, 2018). Estes números, contudo, não refletem com acuracidade o número de indivíduos que efetivamente frequentam as aulas. Logo, pode-se dizer que existe uma discrepância significativa no número de PCDs matriculados no ensino fundamental que não chegam ao ensino médio. Como visto, a legislação brasileira incentiva a permanência de alunos PCDs nas escolas, todavia, apenas 5\%, em média, destes estudantes que entram na escola chegam ao ensino médio (OLIVEIRA, 2013).

Mendes (2013 apud OLIVEIRA, 2013) salienta que, além da estrutura física das escolas, também há obstáculos pedagógicos como a formação dos professores, a falta de auxiliares treinados adequadamente aos diferentes tipos de deficiências em sala de aula, a escassez de materiais didáticos apropriados a cada tipo de deficiência, entre outros motivos que podem favorecer a evasão escolar. O Censo Escolar do MEC 2017 não atenta às informações acerca da quantidade e qualificação de profissionais de AEE 
e sobre a estrutura, como salas de recursos multifuncionais disponibilizadas à população PCD brasileira (MEC, 2018).

\section{PCDs E O ACESSO AO ENSINO SUPERIOR BRASILEIRO}

A partir do exame da conjuntura legal brasileira, percebe-se que a menção à educação superior, nos primórdios, era superficialmente abordada em trechos das leis que referenciavam "a educação para todos e em todos os níveis" (BRASIL, 1961). A posteriori, em 1996, a Lei de Diretrizes e Bases (LDB) abrange um capítulo específico sobre educação superior. Este capítulo, não obstante, centra-se na estrutura organizacional universitária e não nos aspectos da inclusão de pessoas com deficiência no ensino superior (FREITAS et al., 2017).

Na gênese secular, a educação superior irrompe no cenário legal com uma redação que converge para um contexto que busca atentar para a diversidade e procura a evolução no processo de inclusão (FREITAS et al., 2017). A Convenção sobre os Direitos das Pessoas com Deficiência (CDPD), de 2006, verbi gratia, buscou garantir um sistema de educação inclusiva em todos os níveis (BRASIL, 2009). Para tanto, o Governo Federal Brasileiro lança programas de incentivo à educação.

Posteriormente ao incentivo de programas governamentais como o PROUNI, o ENEM e o FIES, o número de PCDs matriculados no ensino superior obteve um incremento em relação aos anos anteriores. Tais políticas impactaram diretamente no acesso de pessoas com deficiência aos cursos de educação superior (FREITAS et al., 2017). O INEP apontou que, em 2014, o número de matrículas de estudantes PCDs alcançou a marca de 7.828.013, um aumento considerável desde 2004, cujo número de matrículas ficou em 4.223.344 (O GLOBO, 2018). No entanto, ainda não se tem 1\% da população com deficiência cursando ensino superior; dados do MEC/INEP apontam para $0,42 \%$. Não há estatísticas oficiais sobre os índices de conclusão do ensino superior de pessoas com deficiência (FREITAS et al., 2017).

Um ponto abordado por Gomes e Lima (2006) deve ser atentado, o fato de um estudante PCD estar inserido em uma sala de aula não necessariamente implica que ele esteja sendo assistido, tampouco incluído. Szymanski et al. (2009) elucidam este 
ponto com um estudo de caso, no qual os autores discorrem acerca de um indivíduo com histórico de deficiência intelectual que estava matriculado no primeiro ano do curso de Educação Física e há quatro anos o repetia. Neste caso, a problemática apresentada por Szymanski et al. (2009) gera grande insegurança a pais, professores e aos sistemas de ensino, que não possuem orientação de como proceder perante fatos como este. Outrossim, nota-se que não há apenas um, mas diversos pontos a serem revisitados pela legislação e atores que a executam.

\section{ESTRATÉGIAS, MÉTODOS, TÉCNICAS E AÇÕES PEDAGÓGICAS NO ENSINO}

Oliskovicz e Piva (2012) asseveram que o ato de ensinar não, impreterivelmente, garante o aprendizado do receptor; assim, o cerne da atividade se focaliza em quem é ensinado, muito mais do que naquilo que lhe é ensinado (BORDENAVE; PEREIRA, 2001). Diversos autores apontam que é papel do docente identificar as ânsias e expectativas dos estudantes para escolher as estratégias e técnicas pedagógicas adequadas para serem utilizadas no ambiente escolar no delongar do ano letivo (OLISKOVICZ; PIVA, 2012).

Estratégias, métodos e técnicas são termos utilizados para denominar maneiras de lecionar. Estratégia, de acordo com Oliskovicz e Piva (2012), caracteriza-se como uma descrição dos meios disponíveis pelo professor para atingir objetivos específicos; por sua vez, método é a via a seguir para galgar um fim, e ele indica as grandes linhas de ação, sem se deter em operacionalizá-las, que é a função da técnica. Esses autores evidenciam que os métodos e técnicas estão baseados em pressupostos teóricos implícitos e que devem ser aplicados de acordo com os objetivos do docente.

Fato posto, o planejamento das estratégias de ensino deve abarcar, de acordo com Lowman (2007), os seguintes critérios: (i) as características dos alunos, por exemplo, sua faixa etária, o nível de desenvolvimento mental, o grau de interesse, suas expectativas de aprendizagem, (ii) as condições físicas e o tempo disponível, (iii) a natureza do conteúdo a ser ensinado e o tipo de aprendizagem a efetivar-se e (iv) a 
adequação aos objetivos estabelecidos para o ensino e a aprendizagem. Assim, fica demostrado como se anseia ensinar e os modos de incentivo por parte do professor (LOWMAN, 2007).

Retomando o vislumbrado anteriormente, houve avanços na oferta de escolas inclusivas no país, porém, isso não significa que a condução e o pensamento dos docentes tenham se alterado. O ensino inclusivo só será bem-sucedido se os professores estiverem preparados para lidar com as limitações das pessoas de tal maneira que possibilite inseri-los no ambiente escolar satisfatoriamente (LEITE, 2013).

No perfil de docentes, no tocante a PCDs, espera-se que o profissional tenha empatia, busque interação com a família e com a supervisão pedagógica da escola, atente-se a conhecer as características das deficiências e do ambiente de origem dos alunos, saiba desenvolver procedimentos pedagógicos versáteis e aptos para despertar a atenção de todos os estudantes (GLAT; NOGUEIRA, 2003). Leite (2013) corrobora as ideias de Glat e Nogueira (2003) e propõe que as mesmas atividades sejam desempenhadas por todos os alunos, respeitando-se, no entanto, as especificidades de cada um, o estímulo às habilidades e aptidões, o que resultará em frutos positivos na inclusão de todos.

\section{METODOLOGIA}

Esta pesquisa de natureza exploratória permite a familiarização com os sujeitos participantes e suas preocupações explícitas nas ações e opiniões dos professores (POUPART et al., 2010) e possui como objetivo oferecer discernimento e compreensão perante o tema proposto (MALHOTRA, 2012). Este estudo contém características descritivas, o processo de pesquisa é flexível e não estruturado. Considera-se, no quesito temporal, uma pesquisa transversal única, pois a coleta de dados ocorreu apenas uma vez (MALHOTRA, 2012).

O instrumento de coleta de dados se qualifica como uma entrevista semiestruturada, disponibilizado no Apêndice B, e foi empregado para coletar as informações referentes à investigação das estratégias utilizadas por professores do Alto Uruguai Gaúcho na interação com seus alunos PCDs, em fase de acesso ao ensino 
superior, com a sala de aula regular. Minayo (2008) define essa modalidade de instrumento como uma conversa entre dois ou mais interlocutores, iniciada pelo entrevistador e com o objetivo de colher e entender informações importantes para um objeto de pesquisa.

Optou-se nesta pesquisa pela narrativa de professores que atuam ou atuaram na educação de PCDs, no ensino médio, em fase preparatória para o acesso ao ensino superior, no Alto Uruguai Gaúcho. O recorte geográfico foi efetuado por conveniência. A população deste estudo se caracteriza por todos os professores que lecionam para PCDs em fase de acesso ao ensino superior nesta região.

Em parceria com a $15^{\circ}$ Coordenadoria Regional da Educação - Estado do Rio Grande do Sul (15 $\mathrm{CRE} / \mathrm{RS})$, obteve-se acesso ao tipo de deficiência portada pelos estudantes nas escolas de cada município. Entre os tipos de deficiência, nota-se que nos municípios estudados há uma sobreposição da deficiência intelectual perante os demais, por este motivo, esta pesquisa se centra em questões relativas a este tipo deficiência.

Neste caso, duas professoras alicerçadoras do ensino de PCDs no grau médio foram contatadas (via telefone e e-mail). Caracterizando, assim, como a amostra desta pesquisa, que se realizou na região do Alto Uruguai Gaúcho. Na seção seguinte algumas características do recorte geográfico serão exploradas.

\subsection{Alto Uruguai Gaúcho}

A região do Alto Uruguai Gaúcho é composta pelos municípios de: Aratiba, Áurea, Barão de Cotegipe, Barão do Rio Azul, Benjamin Constant do Sul, Campinas do Sul, Carlos Gomes, Centenário, Cruzaltense, Entre Rios dos Sul, Erebango, Erechim, Erval Grande, Estação, Faxinalzinho, Floriano Peixoto, Gaurama, Getúlio Vargas, Ipiranga do Sul, Itatiba do Sul, Jacutinga, Marcelino Ramos, Mariano Moro, Paulo Bento, Ponte Preta, Quatro Irmãos, São Valentin, Severiano de Almeida, Três Arroios e Viadutos.

Entre as cidades, Erechim possui a maior área, a maior população e a maior densidade demográfica, também é a morada de atuação das professoras que 
participam desta pesquisa. Aratiba, com menos de sete mil habitantes, surge no cenário econômico do Estado como o município que mais prosperou no PIB. Todas as cidades, exceto Erechim, possuem uma população abaixo de 20 mil habitantes.

No Quadro 1, apresentam-se as informações de acordo com o nível escolar dos alunos nas escolas que esta pesquisa abrangeu.

Quadro 1 - Dados das Escolas Participantes

\begin{tabular}{|l|l|l|l|}
\hline \multirow{2}{*}{ MUNICÍPIO } & \multicolumn{1}{|c|}{ ESCOLA } & No ALUNOS PCDs EF & No ALUNOS PCDs EM \\
\hline \multirow{2}{*}{ ERECHIM } & Escola A & 13 & 6 \\
\cline { 2 - 4 } & Escola B & 23 & 21 \\
\hline
\end{tabular}

Fonte: Os autores, com base nos dados da $15^{\circ} \mathrm{CRE} / \mathrm{RS}$ (2018).

Como o objetivo desta pesquisa visa a investigar as estratégias utilizadas por professores do Alto Uruguai Gaúcho na interação com seus alunos PCDs, em fase de acesso ao ensino superior, com a sala de aula regular, os dados defrontam as experiências narradas por duas professoras participantes em relação aos 27 estudantes PCDs matriculados no ensino médio em Erechim/RS.

\section{ANÁLISE E INTERPRETAÇÃO DOS RESULTADOS}

A amostra é formada por duas professoras da cidade de Erechim, ambas estão na faixa etária compreendida dos 35 - 45 anos. Com relação ao tempo de trabalho nas escolas, Ana trabalha com o magistério há vinte e oito anos e com educação especial há seis anos. Por sua vez, Paula atua com a docência há vinte e quatro anos e pelo mesmo período trabalha com pessoas com deficiência. Levando-se em consideração o regime de trabalho, ambas as docentes possuem vínculo efetivo com as escolas, Ana como professora e Paula em cargo administrativo (orientadora educacional) há oito anos.

Ana é graduada em Pedagogia, possui pós-graduação em Educação Infantil, outra pós-graduação em Orientação Educacional e uma terceira em Educação Especial. A docente iniciou sua carreira com a educação infantil, contudo, com os 
conhecimentos que obteve na pós-graduação em Educação Especial, optou por trabalhar nesta área, a princípio com a gestão e a posteriori no ensino médio. Atualmente, exercita seu ofício nas salas de recursos com PCDs e atendimento individualizado.

O tempo legal que um estudante pode permanecer na sala de recursos é de duas horas por dia e, no mínimo, duas vezes por semana, que usualmente ocorrem no contraturno do ano regular, descreve a professora. Nesta sala, Ana acompanha o progresso dos estudantes de maneira particularizada, assim a docente analisa quantas/quais atividades e por quanto tempo um aluno realmente consegue acompanhar as informações de acordo com cada limitação.

A professora Ana informa que em uma das escolas que atende há estudantes do ensino fundamental ( $5^{\circ}$ ano) que não conhecem as consoantes do alfabeto e outros de ensino médio que ainda não estão completamente alfabetizados. Para definir suas estratégias de atuação, Ana considera as aspirações dos alunos. No caso do ensino médio, questões de oralidade, interpretação, leitura, escrita, pesquisa, pesquisa online, digitação e formatação são alguns dos pontos mais vislumbrados pela docente. Além disso, Ana menciona que há necessidade de se preocupar com a formação do cidadão, por isso inclui atividades de socialização e busca incentivar o interesse pela escola.

Por exemplo, um dos dezoito alunos do ensino médio atendidos pela docente, expôs que almeja ser professor. Para tanto, as estratégias adotadas visaram ações voltadas ao acesso para ensino superior, como aplicação de simulados para realização do vestibular, preparatório para o ENEM - foco em redação -. O mais importante, segundo a professora, é trabalhar naquilo que o estudante demonstra interesse; como estratégias de ensino, as ações utilizadas por ela são lúdicas (jogos de computador, jogos em grupo...), não apenas no ensino médio, mas em todos os níveis que atua.

Paula possui formação de nível superior em Pedagogia, um curso profissionalizante - MBA em Gestão, pós-graduação em Administração e atualmente é discente do curso de Administração e docente do curso de Pedagogia em uma instituição de ensino superior no Rio Grande do Sul. Iniciou sua jornada de docente 
pelas séries iniciais, sendo que na primeira turma na qual ministrou sua aula havia PCDs de diferentes tipos de deficiência.

Para esta turma específica, a professora adotou a atitude descrita por Glat e Nogueira (2003) como mais apropriada para um docente. Em seu relato, a professora discorre acerca do envolvimento necessário que houve com a família dos estudantes PCDs, da atitude positiva de empatia e das táticas que desenvolveu para contornar os desníveis entre os deficientes e os alunos regulares. Atenta-se para o fato de que a docente teve ciência dos diferentes níveis e maneiras de aprendizagem, portanto, utilizou-se de técnicas lúdicas que prenderam a atenção de todos os alunos.

Apesar da pouca experiência no início de sua carreira, Paula não desistiu e optou por elaborar estratégias de planejamento de suas aulas que abarcassem, um tempo hábil à compreensão, realização da atividade e aprendizagem do conteúdo. De modo a evitar a evasão e ausência de alunos em suas aulas, Paula buscava desenvolver práticas entusiastas nas quais o espírito de equipe e integração da turma era o foco.

Contudo, em determinados momentos, as atividades eram executadas individualmente para que a professora pudesse assessorar os alunos em suas particularidades. Vistos os diferentes níveis de compreensão, eventualmente, a docente elaborava tarefas diversificadas para cada estudante. Algumas das atividades relatadas pela professora eram mais compactas ou menos desafiantes para determinados alunos. Para que o estudante se mantivesse motivado, elogios eram realizados ao final dos exercícios e, em sequência, um desafio era apresentado para estimular o conhecimento. Ana, por sua vez, instrui que os professores apliquem as mesmas atividades avaliativas a todos os alunos, sem distinção. Atenta-se também que deve haver questões que abarquem as dificuldades dos indivíduos PCDs.

De acordo com a narrativa de Paula, a média, hoje, das turmas é de trinta pessoas, sendo que entre elas cerca de quatro possuem algum tipo de deficiência, e a mais corriqueira é a deficiência intelectual. Cinco anos atrás, relata que a incidência de alunos PCDs era de casos isolados. Um dos grandes desafios apresentados pela professora foi a ausência de auxílio e preparo da equipe pedagógica nas escolas onde lecionou, ponto de destaque na narrativa de Ana. 
Ainda salienta a falta de comprometimento que algumas famílias apresentam. Paula discorre em muitos casos sobre o preconceito imbuído na própria casa do estudante, que retarda seu crescimento pleno e se constitui como um cenário impróprio para seu desenvolvimento. A docente afirma que, em determinadas situações, quando o aluno apresenta altas habilidades e superdotação, a família não oferece o devido suporte necessário para o progresso destas crianças e/ou jovens. Ana atenta que muitos dos estudantes são "herdeiros das drogas"; com um histórico familiar abalado, os estudantes que chegam ao ensino especial, por vezes, possuem uma carga genética que os impossibilita de evoluir de maneira completa. Ilustra-se isso com o exemplo abordado por Ana, após o retorno das férias, alguns estudantes necessitam retomar o conteúdo aprendido previamente.

Por estar em um cargo de gestão, a professora Paula menciona que docentes já se negaram a aceitar estudantes PCDs em suas classes, o que é corroborado por Ana. Alguns dos motivos apresentados por eles foram a insegurança em atuar como educador junto a essas pessoas, a indisponibilidade de auxiliares e a falta de formação especializada. De modo a contornar esse tipo de declaração, e por solicitação da $15^{\circ}$ CRE, Paula e Ana afirmam que a instituição investe e incentiva os professores a participarem de diferentes cursos e palestras, sobre os mais diversificados temas, a saber: racismo e cultura afro, autismo, TDAH (transtorno do déficit de atenção com hiperatividade), entre outros.

As educadoras pautam mudanças institucionais que, por mais que estejam sendo realizadas, ainda não são efetivamente eficazes. Paula acredita que os pontos principais que devem ser trabalhados são: a formação dos profissionais - para que estejam aptos a atuar com PCDs; a estrutura das escolas para atender os diversos tipos de deficiência; a necessidade do material didático adequado para cada tipo de deficiência; além de incentivar o entendimento por parte dos familiares em conhecer o trabalho da escola e as especificidades das diferentes etapas de desenvolvimento de cada estudante.

Corroborando Paula, Ana afirma que os docentes não estão preparados para assumir os desafios de uma sala inclusiva. Há relatos de recém-formados de que não há disciplinas na graduação que os informem e formem para como trabalhar com 
PCDs. Outro ponto destacado pela professora é a falta de incentivo, por parte das instituições, para que os professores busquem palestras, formações, cursos fora dos limites da escola.

Ambas as professoras afirmam e ressaltam que os estudantes com deficiência são pessoas que possuem limitações, mas com múltiplas capacidades a serem exploradas e aprimoradas e cabe à sociedade entender e inclui-las.

\section{CONSIDERAÇÕES FINAIS}

A análise dos dados apresenta e reforça as informações da pesquisa e da literatura acerca da temática estudada. Identificam-se, a partir das narrativas das docentes, as metodologias utilizadas nas salas de aula regulares que favorecem o processo de ensino e aprendizagem com PCDs em fase de acesso ao ensino superior. Entre elas, as metodologias lúdicas, com o auxílio de tecnologia, são as mais utilizadas, independentemente do nível escolar do estudante. Algumas técnicas descritas por elas são: jogos, jogos online, questões de oralidade, interpretação, leitura, escrita, pesquisa, pesquisa online, digitação e formatação.

Verificou-se que há mudança na aprendizagem com o uso de recursos didáticos adaptados. Ilustra-se este tópico com o relato de Ana. A mãe de um estudante PCD do ensino médio estava apreensiva com o provável bullying e a possibilidade de o filho dela não aprender os conteúdos por conta de sua deficiência, atrelada ao incerto comportamento dos alunos. Então, essa mãe foi chamada à escola e, para sua surpresa, recebeu elogios das professoras e notou a integração de seu filho com os demais. Paula aponta que ele é o melhor aluno da sala.

Percebeu-se que existem encontros e atividades extraclasses para os alunos PCDs em fase de acesso ao ensino superior na sala de recursos. Nesta, a professora avalia as vontades de cada aluno e molda suas estratégias para complementar a educação regular ofertada no contraturno. Destaca-se aqui que as salas de recurso são da $15^{\circ}$ CRE e estão locadas, estrategicamente, em escolas da região do Alto Uruguai Gaúcho. 
A formação docente relatada por ambas as entrevistadas demostra a necessidade de capacitação para todos profissionais, não vinculada ao nível em que lecionam. As instituições e a equipe pedagógica das escolas precisam incentivar e promover a conscientização e capacitação destes docentes. No tocante à estrutura, fica claro que as escolas do Alto Uruguai Gaúcho- ainda carecem de melhorias.

A partir da emersão de informações acerca dos obstáculos confrontados pelos estudantes PCDs em sua jornada escolar, nota-se que a escola, por vezes, os recebe apenas por força da lei, não estando pronta para acolhê-los de modo adequado. Apesar de inúmeras dificuldades para a criação da atmosfera inclusiva dentro das escolas do Alto Uruguai Gaúcho, observam-se evoluções latentes, por exemplo, há uma sensibilização maior por parte de gestores e alguns docentes para com estudantes PCDs.

De maneira a expandir as barreiras limítrofes do conhecimento acerca de pessoas com deficiência e seu acesso ao ensino superior, sugestiona-se a aplicação da abordagem quantitativa para um vislumbre generalizado do campo nesta região, bem como investigar outros tipos de deficiência defronte às premissas de inclusão, pode acarretar insights benéficos ao campo.

Incluir reivindica ações como a melhora estrutural das escolas e a capacitação do corpo docente, o que inclui a esquipe pedagógica de auxílio a professores em sala de aula. Cabe citar que a legislação brasileira é considerada como a melhor legislação para deficientes nas Américas (BBC BRASIL, 2014). Não obstante, faz-se necessário o apoio da sociedade na conscientização e no auxílio de pessoas com deficiência para que possa haver, não apenas uma escola inclusiva, mas também uma comunidade inclusiva e unida.

\section{REFERÊNCIAS}

BBC BRASIL. Brasil "tem a melhor legislação para deficientes das Américas". 2014 Disponível em: https://bbc.in/2s5CXLX. Acesso em: 20 ago. 2018.

BORDENAVE, J, D; PEREIRA, A. M. Estratégias de ensino-aprendizagem. 22. ed. Petrópolis: Vozes, 2001. 
BRAGA, M.; SCHUMACHER, A. Direito e inclusão da pessoa com deficiência: uma análise orientada pela teoria do reconhecimento social de Axel Honneth. Revista Sociedade e Estado, v.28, n. 2, p. 375-392, 2013.

BRASIL. Decreto no 3.298 de 20 de dezembro de 1999. Alterado pelo Decreto $\mathrm{n}-5.296$ de 2 de dezembro de 2004 - 3/12/2004. Regulamenta a Lei no 7.853, de 24 de outubro de 1989, dispõe sobre a Política Nacional para a Integração da Pessoa Portadora de Deficiência, consolida as normas de proteção, e dá outras providências. Diário Oficial da União. Brasília, 1999. Disponível em: https://bit.ly/2E1Ndre. Acesso em: 21 ago. 2018.

BRASIL. Decreto n 36.949 , de 25 de agosto de 2009. Convenção Internacional sobre os Direitos das Pessoas com Deficiência, em 30 de março de 2007. Diário Oficial da União, Brasília, 2009. Disponível em: https://bit.ly/2YulpUE. Acesso em: 02 jul. 2018.

BRASIL. Lei no 4.024, de 20 de dezembro de 1961. Diretrizes e Bases da Educação Nacional. Diário Oficial da União, Brasília, 1961. Disponível em: https://bit.ly/38n5Yn9. Acesso em: 20 jul. 2018.

BRASIL. Lei no 7.853, de 24 de outubro de 1989. Apoio às pessoas portadoras de deficiência, sua integração social, sobre a Coordenadoria Nacional para Integração da Pessoa Portadora de Deficiência. Diário Oficial da União, Brasília, 1989. Disponível em: https://bit.ly/2P2WYfg. Acesso em: 20 jul. 2018.

BRASIL. Lei no 13.146, de 06 de julho de 2015. Lei Brasileira de Inclusão da Pessoa com Deficiência. Diário Oficial da União, Brasília, 2015. Disponível em:

https://bit.ly/2t31DW5. Acesso em 20 jul. 2018.

BRASIL. Ministério da Educação e Cultura. Secretaria de Educação Especial. Portaria no 948/2007, de 07 de janeiro de 2008. Política Nacional de Educação Especial na Perspectiva da Educação Inclusiva. Diário Oficial da União, Brasília, 2008. Disponível em: https://bit.ly/2rl4OYG. Acesso em: 20 jul. 2018.

COMITÊ NACIONAL DE EDUCAÇÃO EM DIREITOS HUMANOS. Plano Nacional de Educação em Direito Humanos. Brasília: Secretaria Especial dos Direitos Humanos, 2007. Disponível em: https://bit.ly/36olMmJ. Acesso em: 20 jul. 2018.

DECLARAÇÃO de Direito das Pessoas Deficientes. [S.I.:s.n.], 1975. Disponível em: https://tinyurl.com/vmrxq2a. Acesso em 23 jul. 2018.

DECLARAÇÃO de Salamanca: sobre princípios, políticas e práticas na área das necessidades educativas especiais. [S.I.:s.n.], 1994. Disponível em: https://bit.ly/2P4Z2TW. Acesso em: 23 jul. 2018.

FREITAS, S.; FOSSATI, P.; KORTMANN, G. Inclusão com Pessoas com Deficiência (PCD) na Educação Superior: um olhar a partir das políticas de inclusão. In: GIANEZINI, K.; 
GROSS, J. Estudos contemporâneos em ciências jurídicas e sociais. Florianópolis. Dois por Quatro. Criciúma, 2017. p. 79-97.

GARCIA, R.; BACARIN, A.; LEONARDO, N. Acessibilidade e permanência na educação superior: percepção de estudantes com deficiência. Psicologia Escolar e Educacional, v.22, p. 33-40, 2018. Número especial. Disponível em: http://ref.scielo.org/9hznbd.

GLAT, R.; NOGUEIRA, M. L. de L. Políticas educacionais e a formação de professores para

a educação inclusiva no Brasil. Revista Integração, Brasília, v. 24, ano 14, 2003, p. 22-

27.

GOMES, M. F. C.; LIMA, P. A. L. Inclusão e exclusão: a dupla face da modernidade. In: SEMINÁRIO INTERNACIONAL SOCIEDADE INCLUSIVA, 4., 2006, Belo Horizonte. Anais [...]. Belo Horizonte: 2006.

GONSALVES, E. P. Iniciação à pesquisa científica. 3. ed. Campinas: Alínea, 2003.

LEITE, M. Educação inclusiva na percepção de professores dos anos iniciais do ensino fundamental: um estudo de caso em Escola Pública Estadual de Minas Gerais. In: ENCONTRO DA ANPAD, 37., 2013, Rio de Janeiro. Anais [...]. Rio de Janeiro: ANPAD, 2013.

LOWMAN, J. Dominando as técnicas de ensino. São Paulo: Atlas, 2007.

MALHOTRA, N. K. Pesquisa de marketing: uma orientação aplicada. 6. ed. Porto Alegre: Bookman, 2012.

MARIA. B. $O$ ingresso de pessoas com deficiência no ensino superior ainda é baixo no Brasil. [S.I.]: Midamax, 2018. Disponível em: https://bit.ly/2t3cT4N. Acesso em: 10 ago. 2018.

MARTINS, S. E. S. O.; GOMEZ, A. J. V.; FERNANDES, Y. Z.; BENETTI, C. S. Inclusão de universitários com deficiência na educação superior: o que dizem as pesquisas no Brasil e Uruguai. Jornal de Políticas Educacionais, v. 11, n. 18, nov. 2017, p. 1-23.

BRASIL. Ministério da Educação. Censo Escolar da Educação Básica 2016. Brasília: INEP, 2016. Caderno de Instruções.

BRASIL. Ministério da Educação. Censo Escolar da Educação Básica 2017. Brasília: INEP, 2017. Caderno de Instruções.

O GLOBO. Aumenta inclusão de alunos com deficiência, mas escolas não têm estrutura para recebê-los. Jornal O Globo, 2018. Disponível em: https://glo.bo/2DZfdvH. Acesso em: 06 ago. 2018. 
OLISKOVICZ, K.; PIVA, C. As Estratégias didáticas no ensino superior: quando é o momento certo para se usar as estratégias didáticas no ensino superior? Revista de Educação, v.15, n.19, 2012, p. $111-127$.

OLIVEIRA, C. Só $5 \%$ das crianças com deficiências que entram na escola chegam ao ensino médio. Rede Brasil Atual, 2013. Disponível em: https://bit.ly/2P6CD8N. Acesso em 25 set. 2018.

POUPART, J et al. A pesquisa qualitativa: enfoques epistemológicos e metodológicos. 2. ed. Tradução de Ana Cristina Arantes Nasser. Petrópolis: Vozes, 2010.

ERECHIM (RS). Educação. Erechim: órgão oficial do município, 2019. Disponível em: https://bit.ly/2DYKuyH. Acesso em: 20 ago. 2018.

SANTOS, L.F. Educação de pessoas com deficiência: o que diz a lei? [S.I.]: Fundação Maurício Sirotsky Sobrinho, 2017. Disponível em: https://bit.ly/2E1sHas. Acesso em: 20 jul. 2018.

SZYMANSKI, M.; IACONO, J.; PELLIZZETTI, I. Deficiência intelectual e inclusão no ensino superior: novos desafios. CONGRESSO BRASILEIRO MULTIDISCIPLINAR DE EDUCAÇÃO ESPECIAL, 5., Londrina. Anais [...]. Londrina: [s.n.], 2009.

VIANA. T. Discriminação ainda é a maior barreira para acessibilidade. Diário do Nordeste. 02 dez. 2017. Disponível em: https://bit.ly/38mhYFn. Acesso em: 15 ago. 2018. 